\title{
A CAPOEIRA DOS MESTRES PASTINHA, BIMBA E COBRINHA VERDE NO ACERVO DO MUSEU AFRO-BRASILEIRO DA UFBA
}

\section{THE CAPOEIRA OF MASTERS PASTINHA, BIMBA AND COBRINHA VERDE IN THE COLLECTION OF AFRO-BRAZILIAN MUSEUM OF UFBA}

\author{
Joseania Miranda Freitas ${ }^{1}$ \\ José Joaquim de Araújo Filho \\ Jean Herbert Batista Brito ${ }^{3}$
}

\begin{abstract}
Resumo: Este texto apresenta algumas reflexões sobre o estudo da Coleção de Capoeira do Museu Afro-Brasileiro, da Universidade Federal da Bahia, MAFRO/UFBA. Esta coleção abarca peças pertencentes a três importantes mestres baianos, que começaram a jogar capoeira nas primeiras décadas do século XX, momento histórico em que ainda era considerada uma atividade marginal.
\end{abstract}

Palavras-Chave: Capoeira; Museu; Patrimônio.

\begin{abstract}
This paper presents some reflections on the study of Capoeira Collection at Afro-Brazilian Museum of Federal University of Bahia ("MAFRO/UFBA"). This collection includes pieces belonging to three important Bahian masters who began to play capoeira in the first decades of the twentieth century, the historical moment when it was still considered a marginal activity.
\end{abstract}

Keywords: Capoeira; Museum; Heritage.

\footnotetext{
${ }^{1}$ Doutora em Educação. Professora do curso de Museologia, coordenadora do Programa de Pós-Graduação em Museologia e pesquisadora do Museu Afro-Brasileiro/UFBA. E-mail: joseania@ufba.br

${ }^{2}$ Graduando em Museologia/UFBA, bolsista de Iniciação Científica, PIBIC/CNPq. E-mail: jjfilho2@ yahoo.com

${ }^{3}$ Graduando em Museologia/UFBA, bolsista de Iniciação Científica, PIBIC/FAPESB. E-mail: jhanherbertt@gmail.com
} 
A capoeira é patrimônio, não pode perder o seu valor.

(Vicente F. Pastinha - frase no estandarte da Coleção MAFRO).

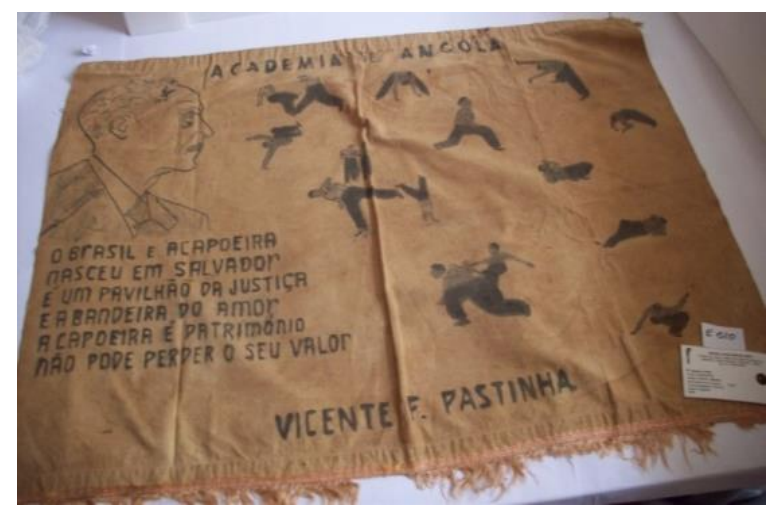

Imagem 1: Estandarte da Academia do Mestre Pastinha (Foto institucional).

As sábias palavras do Mestre Pastinha apontavam, décadas atrás, para o reconhecimento da capoeira com patrimônio brasileiro e para a necessidade de cuidados como a sua preservação, para que seu "valor" não se perdesse. Entre os argumentos valorativos destacam-se as memórias, trazidas nos corpos e mentes da gente africana, escravizada pelo sistema colonialescravista, responsáveis pela criação e recriação do que se constitui como "cultura nacional". Neste sentido, a capoeira, como uma das formas de expressão cultural, sintetiza elementos das rítmicas musicais, dos instrumentos e vozes, através do jogo de corpo, que se transforma em dança ou luta. Assim, a premissa de reconhecimento - gravada no estandarte da Academia veio a se oficializar em 2008, quando a capoeira foi reconhecida pelo Instituto do Patrimônio Histórico e Artístico Nacional - IPHAN - como patrimônio cultural do Brasil. ${ }^{4}$

As peças que formam a Coleção "Capoeira do Museu Afro-Brasileiro" são testemunhos da capoeira praticada no século XX na Bahia, pelos Mestres Pastinha (Vicente Joaquim Ferreira Pastinha), Bimba (Manoel dos Reis Machado) e Cobrinha Verde (Rafael Alves França). Destacam-se dois aspectos importantes na formação dos conjuntos de peças dos mestres; pri-

\footnotetext{
${ }^{4}$ Mais informações em: http://portal.iphan.gov.br
} 
meiro: os mestres estavam atentos ao registro da prática da capoeira, guardando documentos, fossem objetos tridimensionais ou registros em suporte papel, como fotografias, fotomontagens, carteiras das academias, registro de alunos, livros e papéis diversos; o segundo aspecto está no cuidado dos familiares em reunir e entregar as peças para a salvaguarda numa instituição oficial de registro de memórias, o Museu Afro-Brasileiro, entre os anos de 1983 e 1984. Nos dois aspectos fica evidente, não somente a sensibilidade, mas principalmente a explicitação de uma lógica preservacionista. Estes aspectos, portanto, não são omitidos no trabalho museal, pois caracteriza a dinâmica do trabalho de pessoas comprometidas com as formas de registro destas peças, anterior à transformação dos conjuntos de peças em acervo museológico.

Estas peças - 23 de Pastinha, 21 de Bimba e 26 de Cobrinha Verde - estiveram em exposição até 1995 (imagens 1 e 2), quando o museu passou pela primeira reestruturação da exposição de longa duração. Aquele momento também foi marcado pela perda de espaços físicos nas instalações gerais do Museu. Essa reestruturação durou dois anos, orquestrada por um projeto que incluía a instalação da Sala da Herança Afro-Brasileira, que daria destaque às coleções de Capoeira, Irmandades, Quilombos, Movimentos Negros, Afoxés e Blocos Afro. No entanto, com a falta de espaço para uma sala que pudesse abrigá-las, as peças foram acondicionadas e armazenadas na Reserva Técnica 5 .

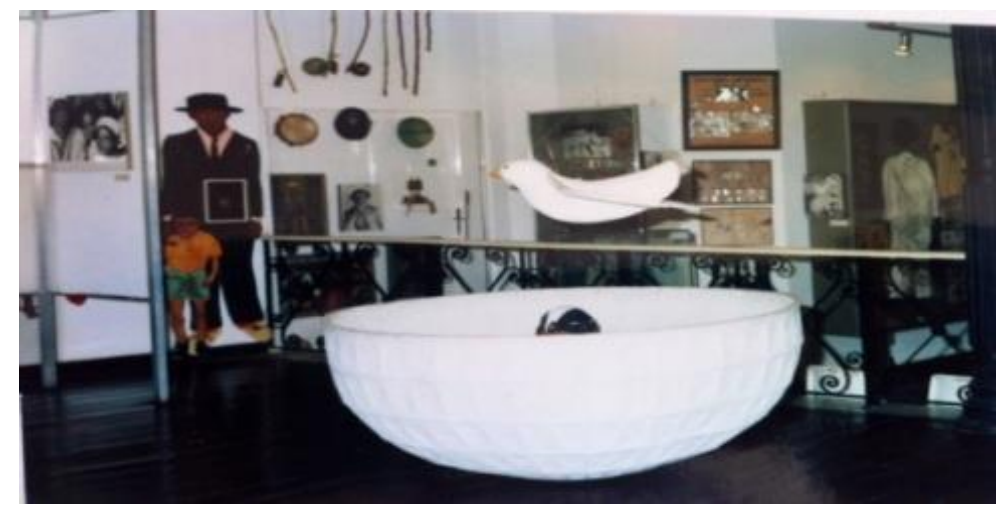

Imagem 2: Exposição Capoeira (Foto institucional).

\footnotetext{
${ }^{5}$ A nova Reserva Técnica, que atende aos padrões técnicos, foi inaugurada em 2009 - através de um projeto de apoio do BNDES. Mais informações sobre o MAFRO em: http://www.mafro.ceao.ufba.br/
} 


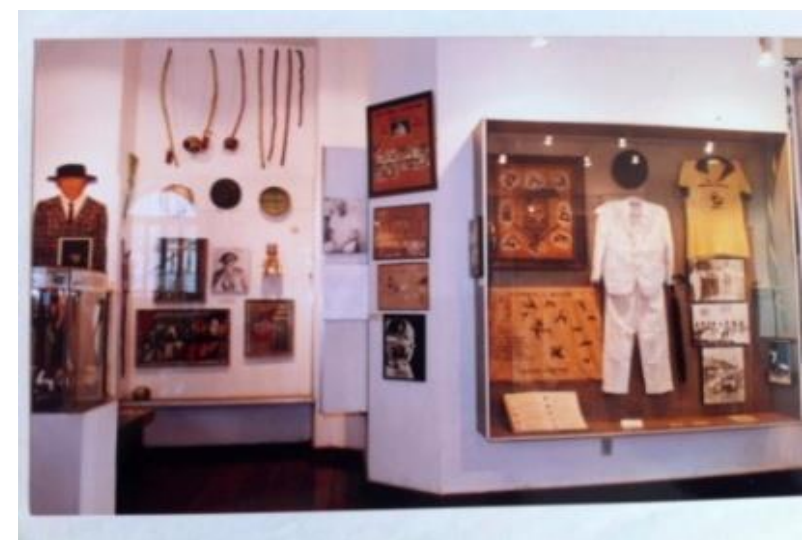

Imagem 3: Exposição Capoeira (Foto institucional).

Uma das marcas do ser humano é a sua capacidade para produzir artefatos, ou seja, transformar matérias primas em diversificados artefatos. Quando retirados do seu contexto original, para o qual foram concebidos, eles perdem a sua relação funcional e passam a ser signos da cultura, sem, no entanto, dissociar-se das relações sócio-políticas para as quais foram produzidos. Uma das características dos museus é trabalhar com conjuntos de objetos e/ou artefatos que perderam as suas funções, mas que continuam sendo portadores de informações: algumas delas intrínsecas, presentes fisicamente nos próprios objetos e/ou artefatos, e muitas outras extrínsecas, advindas da trama de relações, que o processo de pesquisa pode oferecer.

O processo de pesquisa é revelador das tramas das relações sociais e políticas pelas quais os sujeitos e os artefatos se constituem, seja de forma isolada ou em conjunto. Revela ainda as marcas identitárias de quem produziu os artefatos, os utilizou e os salvaguardou, possibilitando também a abertura de outros campos de investigação: a exemplo dos contextos, que levam à explicitação dos tempos e espaços com os quais as peças estabeleceram - e ainda estabelecem - relações.

Neste sentido, a coleção apresenta dados relativos, não somente aos tempos e espaços vivenciados pelos mestres, mas revelam também o seu horizonte social, na expressão de García Blanco (1994). No caso específico do estudo das peças dos Mestres Pastinha, Bimba e Cobrinha Verde - coube à equipe de pesquisa o trabalho de tecer argumentos que pudessem 
Pontos de Interrogação, v. 3, n. 2, jul./dez. 2013

Revista do Programa de Pós-Graduação em Crítica Cultural

Universidade do Estado da Bahia (UNEB), Campus II - Alagoinhas - BA

levar à compreensão dos diversos contextos vividos pelos mestres, de forma a descobrir informações sobre a vida das peças antes de sua transformação em acervo museológico.

O estudo das peças da coleção exigiu o estabelecimento de nexos entre os artefatos produtos da cultura material, sua vida anterior e sua transformação em objetos museológicos e as diversas memórias, registradas ou não, sobre a vida de cada mestre, sobre a formação das coleções por cada família e suas diversas histórias, individuais e coletivas.

Ao final do processo a coleção passou a ter um caráter autobiográfico, apresentando uma série de dados que levaram à identificação de cada mestre, com a explicitação de suas diferentes formas de praticar e registrar a capoeira, sendo necessário, portanto, subdividi-la, com seus nomes. A constituição das coleções autobiográficas pode também ser compreendida a partir da perspectiva da demolição de mitos, apontada por Frantz Fanon (2008:109): “Os pretos são selvagens, estúpidos, analfabetos. [...] essas afirmações eram falsas. Havia um mito do negro que era preciso, antes de mais nada, demolir."

Como "demolidores" de preconceitos, estes três homens negros, que vivenciaram o racismo institucional explícito, conseguiram provar para a sociedade a importância da capoeira que praticavam, e com muita sensibilidade conseguiram registrar, nos diversos suportes, a história da capoeira baiana e sua relação com a cultura nacional e sua expansão internacional.

A Coleção Mestre Pastinha é composta por 23 peças. Este Mestre, que nasceu no ano da abolição da escravatura, foi marcadamente um homem do seu tempo, trabalhou pela efetiva conquista da abolição, que existia por lei, mas que na vivência cotidiana precisava ser conquistada a cada dia. Sua Capoeira, batizada Capoeira Angola, apresentava no nome uma referência explícita ao continente africano e à história da escravidão: motivos pelos quais as peças de sua coleção expressam a necessidade do mestre provar - para a sociedade - o caráter cívico de brasilidade da capoeira.

A Coleção Mestre Bimba, composta por 21 peças, expressa a sua grande preocupação em tirar a capoeira da clandestinidade, pois desde o final do século XIX era considerada como crime, no artigo 402 do Código Penal da República (1890); chegando a ser punido, com até seis meses de prisão, aquele que a praticasse, nas ruas ou nas escolas de capoeira, como informa Santos (2002). A coleção mostra a sua luta pela transformação da capoeira em uma 
manifestação cultural que, além de esporte e dança folclórica, fosse também um "estilo revolucionário", segundo Campos (2006).

A Coleção Mestre Cobrinha Verde, composta por 26 peças, é marcada pela sua expressão religiosa. Entre as variadas peças destacam-se imagens iconográficas que remetem ao sincretismo religioso. A policromia, verde e amarela, revela a importância dos elementos cívicos de brasilidade da Capoeira na Bahia.

Setenta peças formam as coleções dos mestres, distribuídas da seguinte maneira:

Utensílios - inclusive uma peça de mobiliário

Peças de vestuário, incluindo acessórios como bengalas e guarda-chuva

Instrumentos musicais - especificamente berimbaus, pandeiros e reco-recos

Artefatos artísticos, quadros de autoria de Mestre Cobrinha Verde, e desenhos retratando passos de capoeira, feitos pelo Mestre Pastinha

O acervo iconográfico é composto por 27 fotografias e fotomontagens, classificadas como construções artísticas, documentos referentes às Academias de Mestre Pastinha e de Mestre Bimba e seis peças classificadas como "diversos".

Destacam-se neste acervo iconográfico:

- $\quad$ Foto de Mestre Bimba apertando a mão do presidente Getúlio Vargas, no Palácio do Catete, como um documento sobre o novo status da Capoeira: como um esporte, fora da ilegalidade.

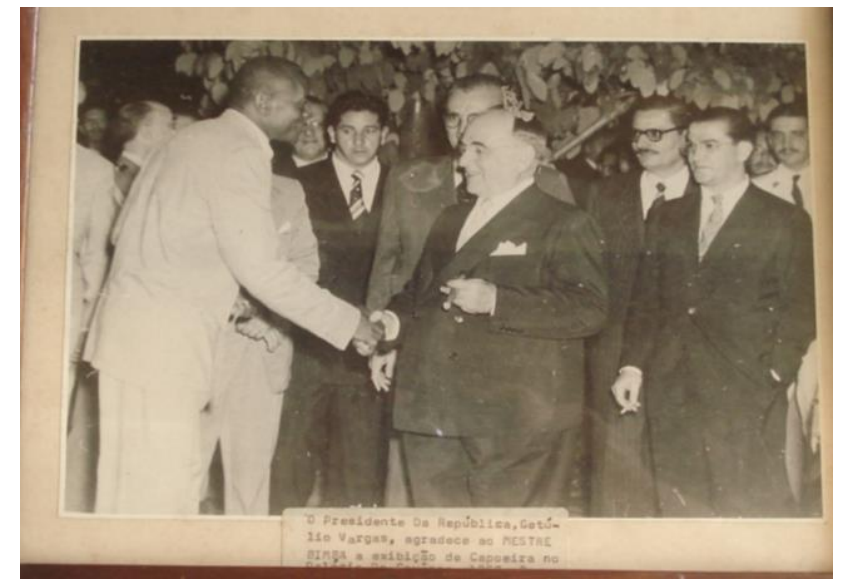

Imagem 4: (Foto institucional). 
- Dentre as fotos de Mestre Pastinha, destaca-se uma - em que ele aparece com roupas de linho branco (que também fazem parte da coleção), que não apenas indicam a sua hierarquia de mestre, mas também o seu grau de habilidade: pois o bom capoeirista era aquele que jogava sem sujar suas vestes.

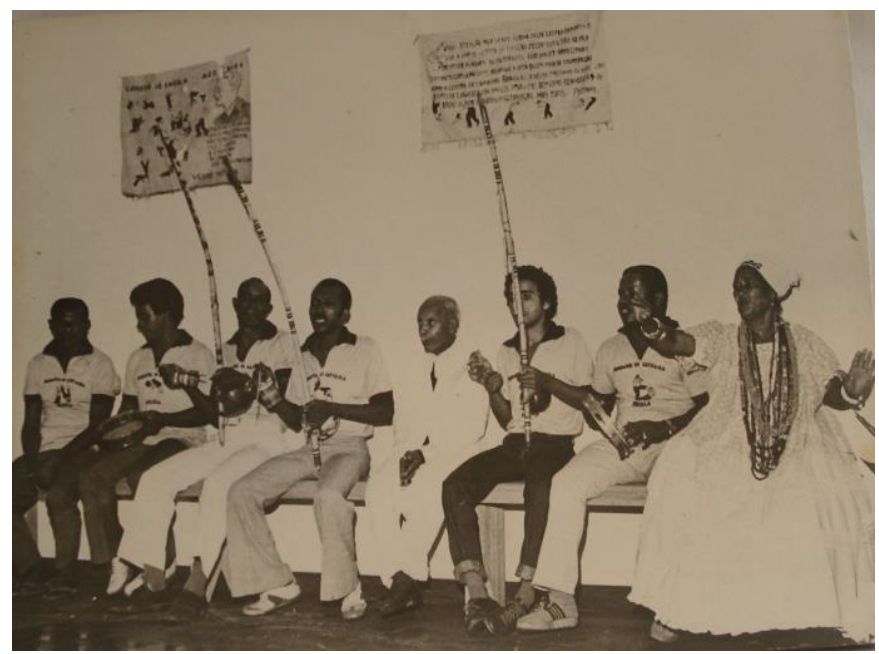

Imagem 5: (Foto institucional).

- Foto de Mestre Cobrinha Verde, revelando seu tipo físico, franzino e aparentemente frágil, mostrando que isso não interferia - em nada - em seu potencial e habilidade para a prática da Capoeira.

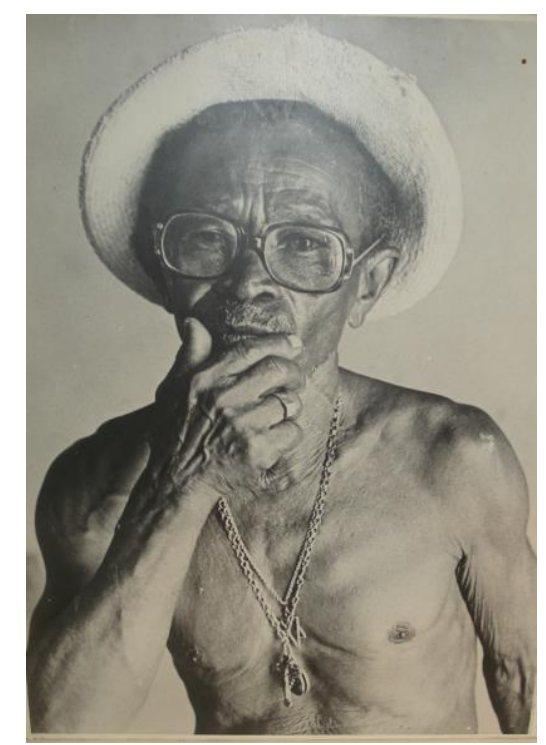

Imagem 6: (Foto institucional). 
O processo de pesquisa teve início em 2003, com o levantamento bibliográfico, realizado pelas estagiárias Livia Baêta, Iraci Oliveira e Valéria Cruz. Após um intervalo, foi retomado em 2011-12, com as bolsistas de Iniciação Científica (PIBIC/CNPq e PIBIC/FAPESB), Dora Maria Galas e Sandra Kroetz, que realizaram a revisão da documentação museológica. A terceira e quarta etapas, 2012-13 e 2013-14, tiveram a participação dos bolsistas José Joaquim Araújo Filho e Jean Herbert B. Brito, sendo que o trabalho realizado nesta última etapa resultou na produção de um projeto específico para elaboração do catálogo sobre a Coleção Capoeira.

Para efetivar a elaboração do Catálogo, foram realizadas, em 2013, sessões de estudo, denominadas de Rodas de Conversa sobre a Coleção Capoeira do MAFRO, que reuniram 39 estudiosos e mestres de capoeira para a escrita de 35 textos e depoimentos (resultantes de entrevistas), que foram organizados de forma a oferecer - aos leitores -um panorama histórico e social sobre a capoeira, através do estudo dos artefatos desta coleção.

Como fios condutores da narrativa temática, os artefatos e as memórias sobre as coleções dos mestres são apresentados nos textos do Catálogo, nas seguintes categorias:

$\checkmark$ Textos biográficos e depoimentos

$\checkmark$ História da Capoeira

Capoeira como Patrimônio

Ações Museológicas com o acervo de Capoeira

Poesias e contos

Música na Capoeira

Indumentária na Capoeira

Capoeira e Educação

$\checkmark$ Filosofia da Capoeira

O espaço das Rodas de Conversa sobre a Coleção Capoeira do MAFRO, funcionou como um fórum de discussões em que eram apresentadas novas informações sobre a vida dos mestres e de seus artefatos, assim como novos questionamentos eram postos, tendo em vista que o campo cultural é pulsante e aberto para novas interpretações. Nesses encontros desta- 
Pontos de Interrogação, v. 3, n. 2, jul./dez. 2013

Revista do Programa de Pós-Graduação em Crítica Cultural

Universidade do Estado da Bahia (UNEB), Campus II - Alagoinhas - BA

cam-se a vivência e a compreensão da capoeira como um "fenômeno sociocultural"; e o conceito de cultura como "dialético", sem hierarquias e oposições binárias entre o popular e o erudito, como chamam atenção as argumentações de Hall (2003:341-342) sobre a cultura negra: “[...] nunca pode ser simplificada ou explicada nos termos das simples oposições binárias habitualmente usadas para mapeá-la [...]”.

Ao analisar dinâmicas culturais - como a capoeira, é preciso não esquecer o contexto de sua criação, a sociedade escravista colonial e seus desdobramentos racistas pós-coloniais, no qual mulheres e homens tiveram que se reinventar, como assinalam as palavras de Zapata Olivella (1989:110.): “[...] o negro devia fabricar sua própria bússola, improvisando-a a partir de sua dor, de sua memória ancestral, de seu poder criador. Foi o que fez com sua filosofia, seus mitos e experiências." A manutenção da prática da capoeira é um exemplo do "poder criador" dos afrodescendentes que, utilizando a "bússola" de suas memórias ancestrais, construíram novas formas de sociabilidade e de sobrevivência no "novo" mundo.

O estudo dos artefatos e/ou objetos das coleções dos mestres, de forma intrínseca e extrínseca, se constitui num caminho para que os objetos possam se comunicar, de forma polifônica e polissêmica. A capoeira evoca memórias ancestrais, memórias que se expressam no campo simbólico, através das lembranças - e memórias no campo tangível, impregnadas nos objetos e/ou artefatos, como sinalizam as palavras de Meneses (1998:90): “A natureza física dos objetos materiais traz marcas específicas à memória”. A força destas marcas torna-se matéria prima para a elaboração de uma série de análises que entrelaçam a vida dos mestres às peças das coleções.

Como exemplo do caráter indissociável entre as memórias e a materialidade dos objetos e/ou artefatos, é possível citar o caso do estudo de um berimbau policromado, encontrado na Coleção do Mestre Pastinha, de formas que , após algumas reflexões na dinâmica das Rodas de Conversa sobre a Coleção Capoeira do MAFRO, foi possível inferir que o mesmo poderia ter sido um presente, alusivo às cores utilizadas na Academia: uma vez que o mestre não utilizava pinturas, afirmando que a tinta poderia interferir na qualidade do som. 


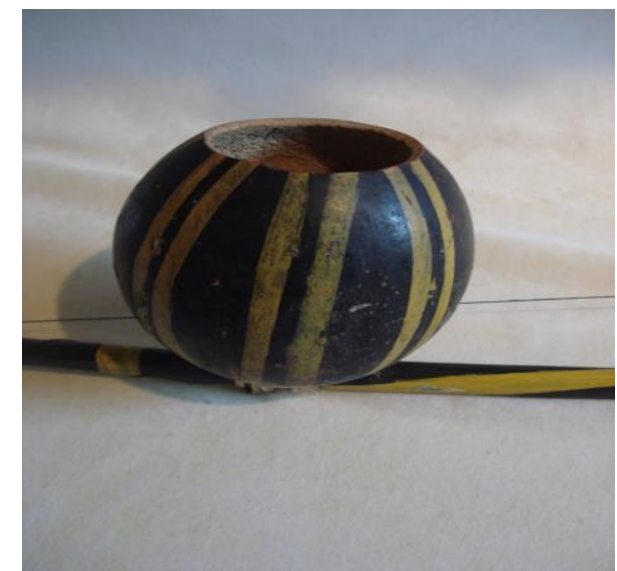

Imagem 7: (Foto institucional).

O uso das cores amarelo e preto aparece no uniforme do CECA - Centro de Capoeira Angola, como referência às cores do Esporte Clube Ypiranga, time do coração do Mestre.

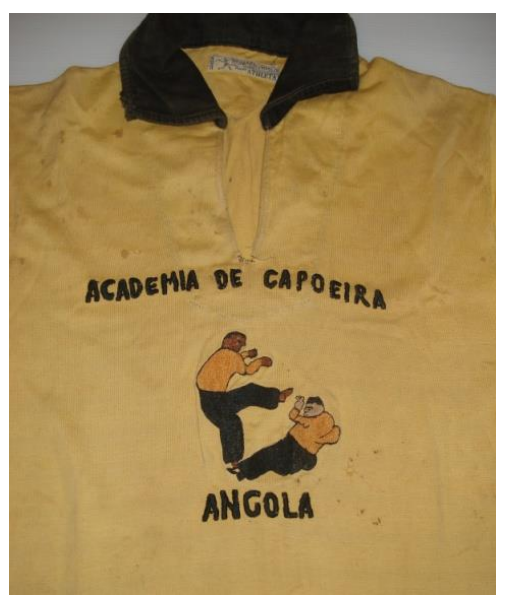

Imagem 8: (Foto institucional).

A pesquisa possibilitou a realização do trabalho de revisão e sistematização da documentação e a elaboração do catálogo (ações museológicas comprometidas com o estudo dos objetos museais), de forma a ultrapassar o campo das informações meramente intrínsecas, adentrando no campo extrínseco, através do exercício de conexão entre objetos e/ou artefatos e suas memórias. Na sequência, discussões teóricas e analíticas, concernentes ao campo museal, foram debatidas com o objetivo de enriquecer as abordagens teóricas e metodológicas para o planejamento da futura exposição, tendo em vista que a expografia, a parte mais visível 
dos museus, tem importância estratégica, cabendo a esta técnica da Museologia, como assinala Cury (2005: 368): “[...] a maior responsabilidade por mediar a relação entre o homem e a cultura material".

A elaboração deste texto, a seis mãos, numa parceria entre orientadora e bolsistas, é resultante de um processo de pesquisa museológica, no qual foram seguidos caminhos metodológicos em busca da compreensão das dinâmicas culturais que configuram a capoeira como uma herança cultural afro-brasileira, como um patrimônio que "[...] não pode perder o seu valor", retomando as palavras do Mestre Pastinha. Nesta perspectiva, o MAFRO/UFBA, ao realizar a nova sistematização documental e planejar a nova expografia para a Coleção de Capoeira, destacando o caráter biográfico dos três mestres, oferecerá a seu público um importante conjunto documental, que servirá como fonte inesgotável de informações das memórias afro-brasileiras.

\section{REFERÊNCIAS}

CAMPOS, Hélio José Bastos Carneiro de. Histórias da Academia de Mestre Bimba: o cotidiano da aprendizagem. Tese de Doutorado apresentada ao Programa de Pós-Graduação em Educação. Universidade Federal da Bahia. 2006.

CURY, Marília. Comunicação e pesquisa de recepção: uma perspectiva teóricometodológica para os museus. São Paulo: História, Ciências, Saúde - Manguinhos, v.12, suplemento, 2005.

FANON, Frantz. Pele negra máscaras brancas. Tradução de Renato da Silveira. Salvador: EDUFBA, 2008.

BLANCO, Ángela García. Didáctica del museo: el descubrimiento de los objetos. Madri: Ediciones e la Torre. 1994.

HALL, Stuart. Da Diáspora: identidades e mediações culturais. Belo Horizonte: UFMG Editora, 2003.

MENEZES, Ulpiano T. Bezerra de Menezes. Memória e cultura material: documentos pessoais no espaço público. Estudos Históricos: memória e cultura material. Rio de Janeiro. CPDOC/Fundação Getúlio Vargas. 1998. Disponível em: http://virtualbib.fgv.br/ojs/index.php/reh/article/viewArticle/2067 
SANTOS, Esdras Magalhães do. Mestre Damião. A verdadeira história da criação da luta regional baiana do Mestre Bimba. São José dos Campos, 2002. Disponível para download no site da ACCPPA: http://www.cppa.com.br

OLIVELLA, Manuel Zapata. Las claves mágicas de América. $2^{\mathrm{a}}$ ed. Bogotá: Plaza \& Janés, 1989.

Recebido em: 18 de novembro de 2013.

Aprovado em: 12 de dezembro de 2013. 